\title{
Nanobubbles for tumors: imaging and drug carriers
}

\author{
Rongxia $\mathrm{Wu}^{1}$, Xiaotong Yang ${ }^{1}, \mathrm{Xiu}^{\prime} \mathrm{e} \mathrm{Li}^{1}$, Naijun Dong ${ }^{1}$, Youping $\mathrm{Liu}^{1}$, and Peng Zhang ${ }^{1}$ \\ ${ }^{1}$ Affiliation not available
}

October 20, 2020

\begin{abstract}
The development of nanobubble technology provides a good means for tumor diagnosis and treatment. In this review, the research and development progress of nanobubbles is discussed. On the one hand, they can be used as a good contrast agent for tumors and effectively visualize the shape of tumors. On the other hand, due to its good water solubility, high drug loading rate and stability, it is used for the delivery of anti-tumor drugs, mainly including oxygen nanobubbles, which can significantly improve the efficacy of chemotherapeutic drugs through precise administration and targeted reoxygenation in the hypoxic area of the tumor; there are also vapor nanobubbles, which are formed by external forces (such as heat or sound) to induce instantaneous stimulation of nanoparticles, destroy the structure and release drugs to achieve therapeutic effects. Nanobubbles can also be used in combination therapy with other drugs. It is expected that this review will provide new ideas for tumor applications based on nanobubble technology and promote the process of tumor treatment.
\end{abstract}

\section{Hosted file}

Manuscript.pdf available at https://authorea.com/users/368874/articles/487867-nanobubblesfor-tumors-imaging-and-drug-carriers

\section{Hosted file}

Figure.pdf available at https://authorea.com/users/368874/articles/487867-nanobubbles-fortumors-imaging-and-drug-carriers

\section{Hosted file}

Table.pdf available at https://authorea.com/users/368874/articles/487867-nanobubbles-fortumors-imaging-and-drug-carriers 